\title{
SIGNIFICANCE OF STRATEGIC PLANNING FOR RESULTS OF SPORT ORGANIZATION
}

\author{
Jovica Petkovic, Edmundas Jasinskas, \\ Laima Jesevičiūtè-Ufartienè
}

\section{Introduction}

In the present day dynamic and competitive environment, organizations are constantly facing the issue of a suitable strategy so that they would timely choose the best business model and would avoid strategy collapse (Hambrick \& Frederickso, 2005; Vargo \& Seville, 2011). In today's world of business and services competition is very high, therefore, in order to function effectively and profitably organizations have to find ways that would enable them to achieve their goals and to compete in the market successfully. When choosing the most appropriate strategy, one of the most important steps is the application of planning activities. Melnikas and Smaliukiene (2007), as well as Schaap (2012) maintain that ability to prepare and implement effective development strategies is becoming the essential factor of organization success allowing expansion and exploitation of strategic advantages and creation of innovative decisions.

Executives of sport organizations can compete in the market more successfully and achieve better activity results in a shorter time period with fewer expenses when the process of organization management includes application of strategic planning activities: determination of vision and mission, creation of specific and real goals, constant environmental analysis, consideration of strengths and weaknesses of the organization, formation of concrete activity strategies and detailed plans for their realization, permanent control and evaluation of the implementation process, as well as revision of strategies.

Probably there is no organization that would not apply strategic planning activities in the management process at least partially. Some organizations are successful in the implementation of the strategy, while others are not. Small and medium businesses without professional management have distinctive characteristics - specific barriers for strategic planning activities are lack of time and experience, insufficient knowledge of about activities of strategic planning, unwillingness to share strategic plans and ideas with employees and with the others, indefinite environment, the size of business, type of industry, internal barriers for implementation, cycles of business lifetime and the level of development (Vasiliauskas, 2004; Volovikov, 2011). Despite the strategic activity barriers small and medium business without an appropriately chosen strategy is vulnerable as it does not accumulate the necessary resources and does not ensure application of competitive advantages (Abdalkrim, 2013; Adamoniene \& Andriuscenka, 2007; Demmings, 2008; Eden \& Ackermann, 2013; Ibrahim et al., 2004, Yusuf \& Saffu, 2005; Schriefer, 2005; Streimikiene \& Kiausiene, 2012; Svagzdiene et al., 2015; Wittmann \& Reuter, 2013; Vveinhardt et al., 2015; 2016). Most often sport organizations employ relatively small staff and the executive has to care not only of the organization strategy, therefore there is lack of strategic activity motivation and the mentioned barriers of strategic activity emerge. Finally, the implementation of strategic planning activities is insufficient.

A problem question: What strategic planning activities are applied by a sport organization and what is the significance of this application for the results?

The aim of the article - to evaluate the significance of strategic planning activities for the results of a sport organization.

To achieve the aim, the following objectives were raised:

1. To distinguish the significance of strategic planning activities for the results of an organization in the theoretical dimension.

2. To analyze and evaluate the application of strategic planning activities in Kaunas sport and leisure clubs. 
The object of the article - application of strategic planning activities.

Methods employed - analysis of scientific literature, questionnaire and statistical analysis.

\section{The Significance of Strategic Planning Activities for an Organization: the Theoretical Aspect}

There exist numerous definitions for: strategy, strategic management and planning that are interrelated. Boar (1995) interpreted strategy as a manager's ability to employ prognostication and management skills in combination in order to achieve highest success. Porter (1996) maintains that a strategy is development and application of valuable strategic positions. In his opinion, creation of strategic positions and their application arise from several sources: 1) variety, 2) needs, 3) access. Beaver (2000) stated that strategy is an extremely difficult, complex and subtle management discipline as it includes risk and uncertainty. It also has to be able to prognosticate future.

Thompson, Strickland and Gamble (2007) define strategy as the action plan of a company management. The authors maintain that a strategy is composed of: 1) occupation of a position in the market, 2) execution of daily operations, 3) attracting of clients and satisfaction of their needs, 4) successful competition in the market, 5) achievement of organization goals ensuring the input of every component into the performance of tasksoperations and their control.

According to Abdalkrim (2013), strategic planning is a complex process involving patience and strong efforts of a team and giving life to the vision and mission when striving for the desired goals and objectives of an organization by facilitating the effective process of decision making, as well as everyday activities. Strategic planning offers the overall picture of what you are doing and where you are going.

Stewart (2002) maintains that strategic planning activities are a source of information, influencing success or failure of organization executives who apply strategies. There is no single definition of strategic planning activities. Different organizations are using diverse strategic planning activities; therefore they are difficult to define (Demmings, 2008).

The following are three strategic planning activities according to Forouzandel (2005):
1. The review of the main strategic principles of an organization;

2. Comparison of expected and actual results;

3. Implementation of correction activities to ensure the accuracy of activities according to the plan.

A slightly more detailed list of strategic planning activities is comprised by Abdalkrim (2013):

1. An independent variable;

2. The definition of a mission;

3. External and internal analysis;

4. Strategy implementation;

5. Strategy control and evaluation.

The Richardson model (Stewart, 2002) is the most comprehensive and including even more activities; it covers eight levels of strategic planning:

1. the mission of an organization,

2. the objectives of an organization,

3. the external analysis of an organization,

4. the internal analysis of an organization,

5. the creation of alternative strategies,

6. the choice of organization strategy,

7. the implementation of organization strategy,

8. control.

The advantage of this model in comparison with Abdalkrim (2013) and Forouzandel (2005) lies in the fact that later Richardson's model identifies four outlines of growth (Stewart, 2002): a) sales/income, b) base of customers/ clients, c) new organizational premises/activity bases, d) employees; therefore it suits perfectly for evaluation of strategic results.

Stewart (2002), having employed Richardson's strategic planning model and the adjusted strategic planning questionnaire, surveyed 100 small companies (up to 500 employees) in the US and determined that official business planning methods had influence on the organization success.

Espinosa (2009) improved Hambright and Diamantes eight step strategic planning model by adding the ninth step - action plan (Fig. 1).

This model, unlike the previous ones, is presented in steps that permanently move in a circle (pre planning, formulation of visionmission, determination of main principles and beliefs, environmental analysis, determination of strategic problems, distribution of strategic problems according to priorities, solutions of strategic problems according to priorities, reasonable guidelines for solution implementation, action plan) and are constantly 


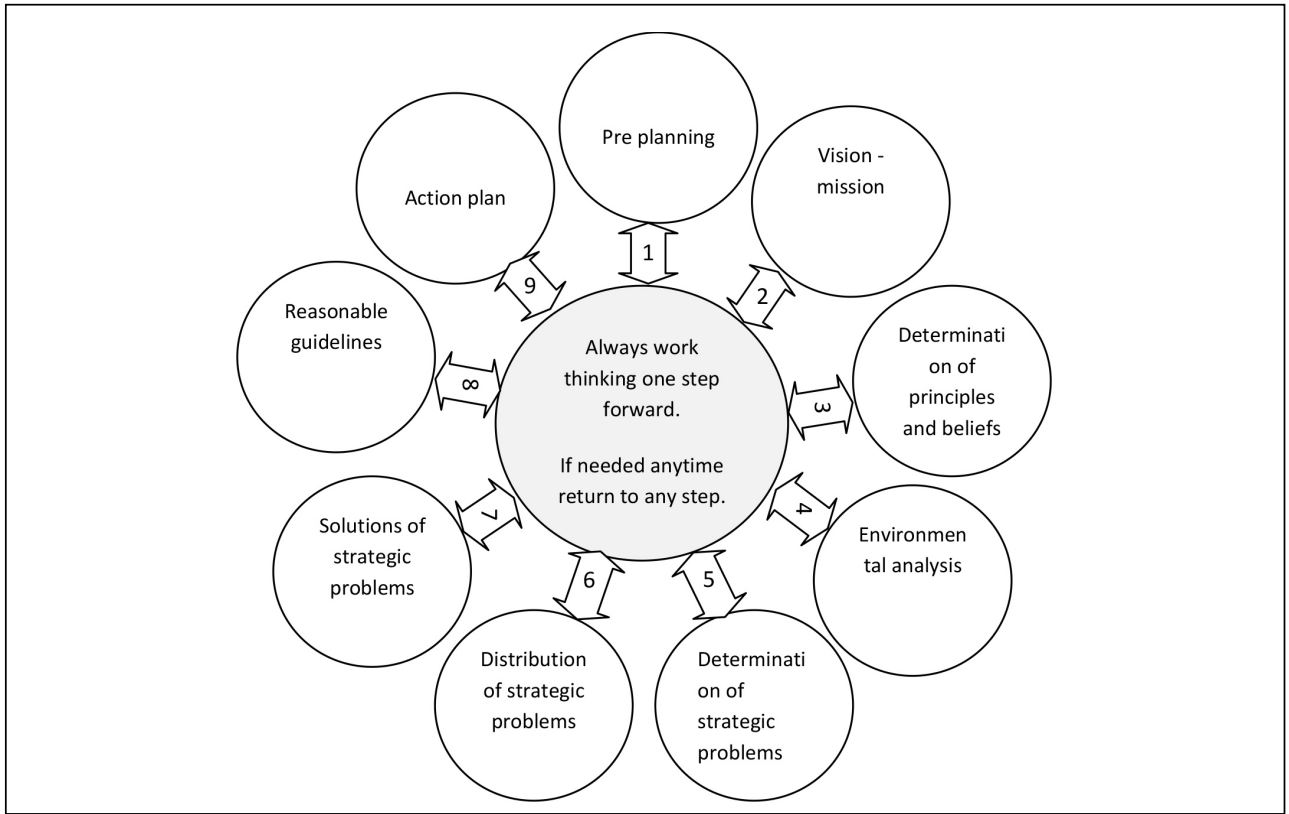

Source: own based on Espinosa (2009)

observed and corrected. Thus the efficiency of the model is ensured. The drawback of the model is that some steps are too small and strongly connected, e.g. determination and distribution of strategic problems, and, therefore, could be transformed into ones of larger scale. In addition, planning activities in this model are not related with results and their control. The activity of the implemented strategy evaluation could be added.

Finally, a strategy is the ability to discover and invent (Pugh \& Bourgeois, 2011). During activities of strategic planning employees of organization are continually learning and gathering knowledge about industry, realized strategies, their abilities, and economical situation. These activities of strategic planning should be able to improve the competitive situation and success of a company.

The previously discussed activities in principle disclose the process of strategic planning. Still it has to be noted that it would be impossible to identify the type of strategy applied by the company according to the performed activities. In this respect business strategy typologies used by Parnell (2003), Miles and Snow (1978) would be more appropriate. Each strategy type defines the relationship between the organization expenses and the scope of activities depending on the leadership direction. Strategy types and respective explanations can be distinguished:

1. Defender strategy. Companies which supported the defender strategy did not introduce innovations and followed the strategy of cost reduction.

2. Innovator / researcher strategy. Companies supporting this strategy followed the more risky strategy type that would increase profit by employing different opportunities stimulating the growth of income.

3. Analyzer strategy. Companies which supported this strategy based their activity on the analysis of mistakes and developed further action accordingly.

4. Reactor strategy. Companies following this strategy made changes only when alterations in the environment were too significant to continue the development of activity in the same mode. 
The differences of these strategic management peculiarities give an opportunity to evaluate the significance of the strategy for the results of an organization. Different researchers signify various aspects of strategic planning activity significance for an organization and its results. Damaskiene (2002), Abdalkrim (2013) maintain that the formation of strategic planning is decided by a number of factors and the way of the organization success in attaining positive business results and endless development opportunities is grounded by constant strategy improvement (Rieker, 2004).

Strategic planning is considered to be the most important component of business success, reflecting the abilities of executives to create vision maintain adaptability and prognosticate the future in the unstable business environment (Demmings, 2008). According to Arimaviciute (2004; 2005), strategic planning also helps to create a rational management system based on the principles of balanced development.

The research shows that the attention of leaders to the implementation of strategic decisions decides profit growth and increases customer satisfaction. When combined with innovations such strategic decisions influence the competitive superiority of an organization (Schriefer, 2005). According to Natzel (2010), implementation of innovations would enable a successful application of a mixed strategic model, oriented towards a conscious decision of executives to connect differentiation price and expenditure control.

The choice and application of strategic planning activity tools can increase the opportunities for small and medium business survival in the competitive business environment and contribute to its growth. Though leaders of small and medium business are striving for success and development, without strategy and tactics they remain vulnerable in connection to the necessary resources and productivity (Demmings, 2008). The environment influences organizations and they change and choose the environment by using organizational strategy in decision making (Scott, 2003). Yusuf \& Saffu (2005) determined that, in comparison with other companies, activity results of small and medium companies improved when an official business plan was started to be used. Rieker (2004) says that the attention for strategic management in small and medium business organizations is necessary in order to improve and develop successfully in the growing markets.

The ability to determine what resources will be necessary and who will supply these resources for the desired development is a very important management skill deciding the strategy of an organization. Knowledge about indispensable resources influences the strategic plan change and implementation. When an innovative leader has ideas and needs that cannot be implemented with the help of own means, a strategic partnership is a perspective decision (Williams, 2012). The strategic decision of an executive to adopt innovations depends on the evaluation of a few influencing factors: a) the need of innovation, b) the relative value of innovation and $c$ ) the threats caused by innovation (Eden \& Ackermann, 2013).

Hutzschenreuter and Kleindienst (2006) identified a connection between strategic planning, decision making, activity implementation, and successful change management. Thus, on the basis of numerous researches, it could be stated that strategic planning is inseparable from successful development of an organization and there are numbers of factors deciding its formation.

When solving the issue of selection of strategy creation means, various strategy creation concepts have to be taken into account. Different researchers classify strategy formation concepts differently by choosing diverse classification objects:

Strategic concepts have been classified into four theories according to orientation to subjective or objective understanding and orientation to the external and internal (Tamasevicius, 1996).

Strategic schools have been classified into three main groups according to usage options: 1) normative (telling what to do), 2) descriptive (explaining why a certain strategy was adopted) and 3) having normative and descriptive features (Mintzberg, 2005).

Strategic schools have been classified into five groups according to strategy creation imperative: 1 . ability to model a situation, 2. ability to disclose the need of changes in a company, 3. ability to prepare the strategy for change; 4 . ability to apply reliable methods in the change period, 5. ability to implement the strategy, 6 . the significance of entrepreneurial imperatives for strategic leadership (Gudonavicius et al., 2009). 
Each distribution of strategic concepts is useful and does not contradict with the rest. Still, Mintzberg's, Ahlstrand's and Lampel's (2005) distribution (three main groups that are subdivided into ten strategic schools) is the most popular among researchers of the field. It was applied by Arimaviciute (2005), Matthews (2005) and others.

Normative strategy school group includes schools of design (projecting), planning and positioning (Mintzberg, 2005). The school of design (projecting) gives exceptional attention to the evaluation of external and internal situation with the help of the classical SWOT analysis (Matthews, 2005). Only proper evaluation of strengths and weaknesses, as well as opportunities and threats helps to achieve positive results. This analysis is grounded on the ability to foresee the development of the situation and create the "map" of future events from separate factors. In addition SWOT analysis is a good diagnostic tool when the scenarios have already been created. This method is applied in all spheres with the exception financial strategic analysis (Gudonavicius et al., 2009). Appropriate evaluation of own strengths and weaknesses, opportunities and threats helps to determine opportunities for the increase of an organization service attractiveness.

Vasiliauskas (2004) maintains that there are two main methodologies in the strategic management literature - deterministic and emergent.

The process of strategic planning covers the organization's mission, vision, goals, creation of strategy, its implementation and analysis, but the strategic management model in deterministic methodology is way more detailed. Unlike the emergent methodology model it distinguishes closely connected stages of strategy creation and implementation, therefore emergent methodology is more flexible. More frequent strategy renewal prevails in the strategic management model of emergent methodology. Here, in a feedback relation, strategy creation and implementation process is connected with the stages of strategic analysis that are distinguished in the model of deterministic methodology.

The model of strategic planning forces the organization to constantly analyze industrial peculiarities which decides long-term organizational success (Ancalade, 2009).
According to Arimaviciute (2005), it could be emphasized that general principles and specificity of strategic management depend on the organization:

- Type of activity (production, services or idea provision);

- Sources of financing (commercial and noncommercial organizations);

- Property (state or privately owned organizations);

- Size (small and large organizations);

- Diversification level (one or several activity fields in a sport and leisure club).

Burgelman and Grove (2006) maintain that it is difficult to relate a strategy with a strategic action. In order to coordinate these things, organizations have to rethink strategies and business models and change traditional ways of business development. To achieve this, strategic decisions have to be made having evaluated environmental factors that could influence the results usually measured by the outcomes of financial activity.

Human resource management has also to be discussed in strategic planning as it is the main auxiliary element in the strategic management of an organization (Ahearne et al., 2014; Jeffrey, 2013; Zafar et al., 2014). Human resource management works for attaining organizational goals in that it places appropriate people with appropriate skills in the right positions in an organization in the right time so that they would reach the set goals and accomplish tasks in the highest quality level (Khoong, 1996). Senior managers most often agree that people and not money or equipment is the main driving force of an organization (Fitzenz, 2000).

The measurement of strategy success in the development of an organization is very complicated. It demands a manifold attitude towards the goals, activity and results of an organization that are connected with the development of each activity and individual staff members (Moulds, 2012).

Four presumptive strategy evaluation criteria could be distinguished (Jucevicius, 1998):

- Strategy consistency;

- Compatibility;

- Reality;

- Superiority.

For the strategic activities to be successful the quality of the available data is exceptionally 
impotent (Bettis, 2014). The success of strategic planning also depends on cooperation with employees, attention to their opinion, discussions about suggestions, their evaluation etc. (Searcey et al., 2010):

- Sharing opinions and criteria how to achieve the goal more successfully (by distinguishing the implementation of separate stages).

- Sharing the feedback about each level of activity (to determine the blank sides that could be reinforced (to create an action plan in discussions how to reinforce them).

- Discussion about organization goals (the goals have to be measurable and specific. They have to be observed and analyzed in order to successfully implement the changes).

- Discussion of a self-evaluation system (to create self-evaluation tools).

- Discussion of the main strategic questions and problems (to make mutual decisions how the present situation could be improved). These discussions result in a common stimulation of more effective development - accomplishment in all discussed strategic planning activities with the management surveillance and assessment (Searcey et al., 2010). Hutzschenreuter and Kleindienst (2006) observe that in scientific research the attention is shifted from strategic planning to new fields thereby emphasizing the positions of individuals participating in strategic activities. Jasinskas, Reklaitiene and Svagzdiene (2013) maintain that thinking employees of an organization are influencing development of their organization. The employees have the closest relation with customers and their qualities are essential for the quality and effectiveness of the organization's activity (Jasinskas et al., 2013). Still, even in this case the activities of strategic planning have to be analyzed, but the field of research has to include the aspect of managers' and other employees' participation in the analysis of strategic planning activities. This aspect could manifest itself in every strategic planning activity.

Jeseviciute-Ufartiene (2010; 2014), Kvedarvicius (2006), suggest that organization management and creation would be shaped with the help of twelve Rac future creation actions, which are: prognostication, floodlighting, projection, programming, planning, scenario making, project implementation, author supervision, expertise, monitoring, organization, management. Jeseviciute-Ufartiene, Mejeryte
Narkeviciene and Widelska (2014) maintained that managers' mind activity as the basic force for organization development should be used in these actions.

There are numbers of strategy planning activities discussed by Espinosa (2009), Stewart (2002), Thompson, Strickland and Gamble (2007) and other researchers. In order for the organization to function profitably and would exploit its competitive advantage, strategy planning activities have to be constantly accomplished; they have to be improved and changed, otherwise they would not correspond with the environmental conditions. When striving for the strategy compatibility with environmental conditions, strategic analysis covering the dynamics of company network and the development of business complexity and cooperation is of utmost importance (Jeffrey, 2013). Analyses showed that there are distinguished various strategic activities thus it is important to identify the main activities that could be distributed as follows: setting goals, strategic analysis, prognostication, strategy selection and strategy implementation (see Fig. 2).

Executive involvement and documentation are signified in the top part of the model. They both can influence each other based on the previously discussed processes and are significant. The results of Schaap's (2012) research confirm the role of executives and personnel in the strategy implementation. Strategic consensus has positive influence on the implementation of the strategic process and frequent communication from top to bottom in the organizational structures reinforces strategic consensus and thinking through nurturing of common views and values.

It has also been determined that senior managers who have been taught strategic planning and implementation are more likely to realize activity goals than those who do not have strategic planning knowledge (Schaap, 2012). Relying on the presented evidence, it could be concluded that in order to achieve excellent results strategy implementation plans have to be clearly defined with precise dates and specific duties for individuals - there have to be people responsible for the accomplishment of the task and for documentation.

The actual significance of a strategy is reflected in the results distinguished by Stewart (2002) and Wittmann and Reuter (2013) according to an organization's ability 


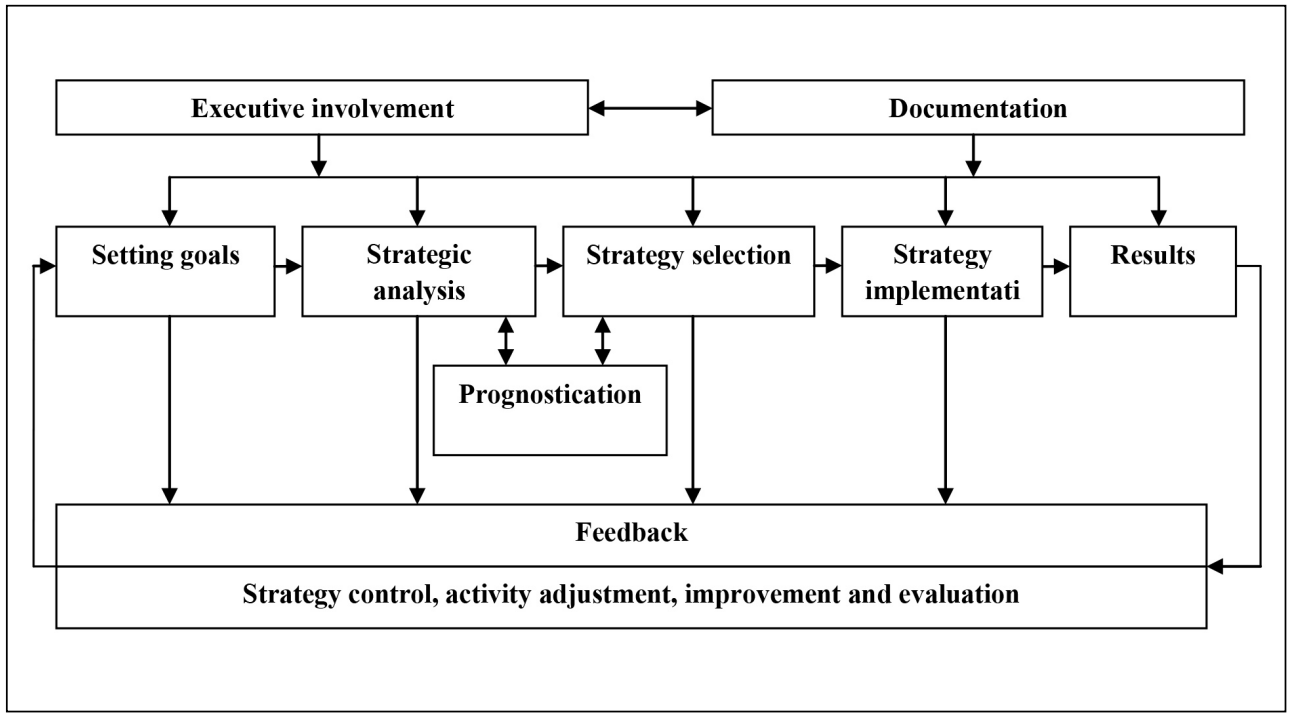

Source: own based on Espinosa (2009), Stewart (2002), Vargo and Seville (2011) and Svagzdiene et al. (2015)

to implement innovative services, expand the network and the scope of clients, create new work places. This data allow the decision to be made about the appropriateness of strategic planning activities.

The model also emphasizes the importance of feedback analysis. Wardwell (2012), Eden and Ackermann (2013) relate strategic feedback analysis with the part of organizational development culture. The results of Inamdar's (2012) research also show the role of control systems and organizational structure is getting more important. The strategy of an organization depends on the feedback and the user needs. The ongoing internal assessments, the encouragement of the organization's staff to keep up with the organization's activities and results and a discussion with them influences the leader of the organization to make the right strategic decisions and thus improve the organization's performance.

The examined models usually focus on feedback, continuous correction of strategic planning activities, their improvement and evaluation; therefore, this model also includes feedback as a separate strategic planning activity.

\section{Research Methodology}

In order to research and evaluate application of strategic planning activities in Kaunas sport and leisure clubs a quantitative expert research - a questionnaire was planned. The instrumentation for the quantitative research was compiled with the help of Seeman's (1972) methodology and a modified Stewart's (2002) strategic planning activity questionnaire was used:

1. Theoretical concepts were selected including setting goals, prognostication, strategy selection, strategy implementation, results and feedback.

2. The main theoretical concepts were divided into conceptual parts (see Fig. 2).

3. Each conceptual part was defined and analyzed theoretically.

4. Research questions according to the Likert scale were formulated for each conceptual part.

The following statistical methods were applied for data analysis: descriptive statistics (frequencies, means), correlation analysis (Pearson correlations), reliability analysis (Cronbach's alpha), and factorial analysis. In order to determine the significance of results, 
two significance levels were chosen, when level of significance is $p: p<0.01$ and 0.01 $<p<0.05$. The methods employed for the result analysis enabled significant exclusion of dependence between individual research questions connected with strategic planning of a sport organization and the efficiency of its activity. Statistically significant correlation coefficients helped to disclose the results of the quantitative research.

Leaders of Kaunas sport and leisure clubs with the experience of at least three years were chosen as respondents for the research. According to Stewart (2002), modern leadersexperts of organizations take up different positions: of a director, deputy director, executive, administrator, etc.

Rudzikiene's (2003) model for expert evaluation standard deflection dependence on the expert number was considered (Fig. 3) and it could be stated that 18 experts are enough for the research results to be regarded as sufficiently valuable and reliable.

Considering a low demand in a respondent sample and having a purpose to analyze innovative sport organizations (using IT technologies), all 25 Kaunas sport and leisure clubs - organizations found in the internet company registration systems (Electronical registration system of VZ organizations, 2014; Lithuanian sport statistics document, 2013; Registration system of Organizations, 2014) were chosen. Kaunas was selected as a target respondent group territory where in 2013 there were 162 sport organizations which 2-3 times more than in the capital of Lithuania - Vilnius and significantly more than in any other region of Lithuania. The experts of 18 organizations out of 25 agreed to participate in the survey. The survey was carried out in July-August 2013. The authors want to express their gratitude for Justas Bradauskas who helped to collect the data.

The reliability of the questionnaire presented for the experts was determined by calculating the Cronbach's alpha coefficient. A questionnaire is considered reliable when the value of the coefficient is at least 0.6; otherwise the questionnaire reliability is low. The value of the Cronbach's alpha coefficient of the created expert evaluation questionnaire is 0.902 . It means that the questionnaire can be considered very reliable.

As a result of factorial analysis and logical thinking respondents were presented with 38 statements divided according to the unifying meanings corresponding with the concepts presented in the model in Figure 2. Based on Pearson's correlation and arithmetic means, relations between strategic management elements and strategic management results were identified and analyzed.

\section{Research Results}

The data of the accomplished research enable the interpretation of the theoretical model (Fig. 2) in the context of sport organizations. With reference to the model in Figure 2 and correlations obtained as a result of the research and statistical analysis, a snapshot of sport organizations' strategic planning and management was made (Fig. 3).

Figure 3 shows that that a goal setting activity could be considered as detached from the strategy in Lithuanian sport organizations because this activity does not have a statistically strong and significant connection neither with the results of the organization, nor with the development of organizational activities. On the other hand, there exists a strong and statistically significant connection among all the remaining elements of strategic planning and management. It is interesting to note that the importance that the respondents attached to goal setting is very high (mean 4.78, Tab. 1). The interpretation of the received results suggests an idea that sport organizations see goal setting as a very important element of strategic management but it is not connected with the organization activity results (correlation 0.363 , Fig. 3) or with the improvement of an organization (correlation 0.243, Fig. 3).

It is likely that goals formulated in the sport organizations do not sufficiently meet the SMART criterion. The formulation of the goal is not sufficiently related with the organization activity results. For this Eason the degree of goal achievement is not evaluated.

It is possible that the formulation of an organization strategy goal expresses the values of the organization more than a specific result to be achieved. This assumption could be made with reference to the received correlations between setting goals and the elements comprising it: mission, goals, and objectives of an organization (Fig. 4).

Statistically strong and significant correlations demonstrate a close connection between strategic goals and the mission that is 


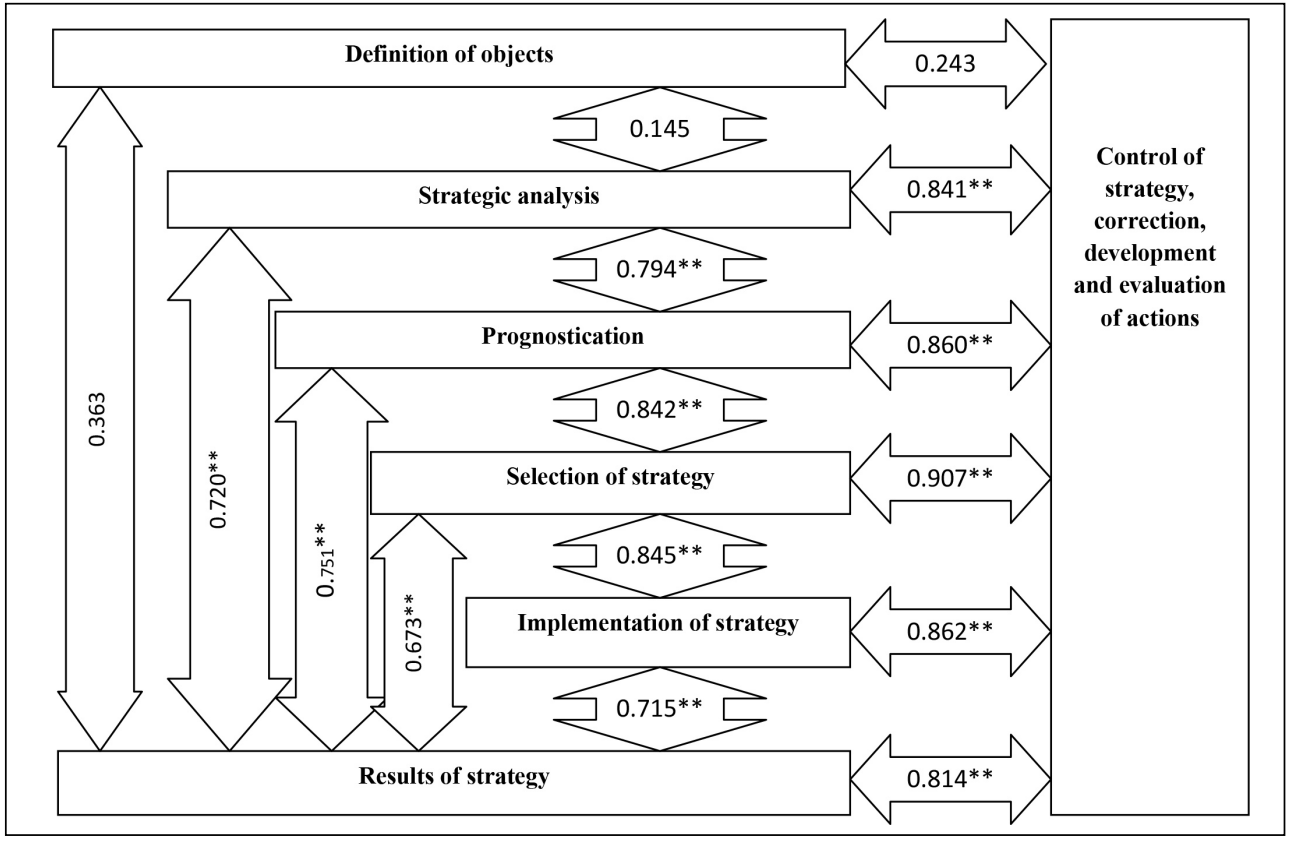

Note: * means $0.01<p<0.05 ;{ }^{* *}$ means $p<0.01$

Tab. 1: Influence of employees' evaluation methods on Essential organization feature

\begin{tabular}{|c|c|c|c|}
\hline & Mean & $\begin{array}{c}\text { Active participati- } \\
\text { on of executives }\end{array}$ & $\begin{array}{c}\text { Documentation } \\
\text { of the plan }\end{array}$ \\
\hline Setting goals & 4.78 & 0.412 & $0.539 *$ \\
\hline Strategic analysis & 3.66 & 0.220 & $0.717^{* *}$ \\
\hline Prognostication & 3.54 & -0.126 & $0.480^{*}$ \\
\hline Strategy selection & 3.82 & 0.213 & $0.731^{* *}$ \\
\hline Strategy implementation & 3.81 & 0.332 & $0.800^{* *}$ \\
\hline Active participation of executives & 4.67 & - & - \\
\hline Results & 3.87 & 0.156 & $0.545^{\star}$ \\
\hline $\begin{array}{l}\text { Strategy control, activity adjustment, } \\
\text { improvement and evaluation }\end{array}$ & 3.72 & 0.213 & $0.639^{* *}$ \\
\hline
\end{tabular}

Note: * means $0.01<p<0.05 ;{ }^{* *}$ means $p<0.01$ 


\section{Fig. 4: Correlation among elements of strategic objects}

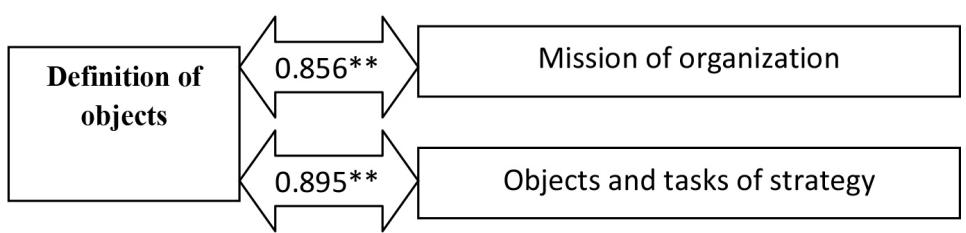

Source: own

Note: * means $0.01<p<0.05 ;{ }^{* *}$ means $p<0.01$

the value foundation of an organization. Goals should be formulated considering the mission but they have to acquire a formula reflecting the result in time. Respectively then strategic goals of an organization could be related with an organization's strategic management results.

Another reason for this kind of research results could be connected with the fact that a statistically significant correlation between the executives' active involvement in strategic management and goal formulation in strategic management was not identified in the research results (Tab. 1), though the respondents named the executives' participation in the process of goal setting as a very important activity in strategic management.

It was determined in the research process that strategic management in sport organizations includes statistically significant correlations between strategic analysis and organization results $\left(0.720^{* *}\right.$, Fig. 3.) and organization improvement activities $\left(0.841^{\star *}\right.$, Fig. 3). The evaluation of strategic analysis of internal elements (Fig. 5) shows a statistically significant and strong correlation with the analysis of internal and external factors carried out in the organization. With reference to such research results it could be stated that Lithuanian sport organizations give sufficient attention to the analysis of internal and external environment.

Strategic analysis carried out in sport organizations is significantly and strongly related with the process of strategy documentation and official registration $\left(0.717^{* *}\right.$, see Tab. 1$)$. On the other hand, an assumption could be made that the process of strategic analysis includes more analytical tasks assigned to employees than the strategic analysis activity that would draw the executives' attention as a statistically significant correlation with the executives' involvement in this process was not identified $(0.220$, see Tab. 1).

The activity of prognostication significantly correlates with strategic analysis $\left(0.794^{* *}\right.$, see Fig. 3), with the selection of strategic alternatives $\left(0.842^{* *}\right.$, see Fig. 3$)$, with the organization results $\left(0.751^{* *}\right.$, see Fig. 3$)$ and

\section{Fig. 5: Correlation among elements of strategic analyses}

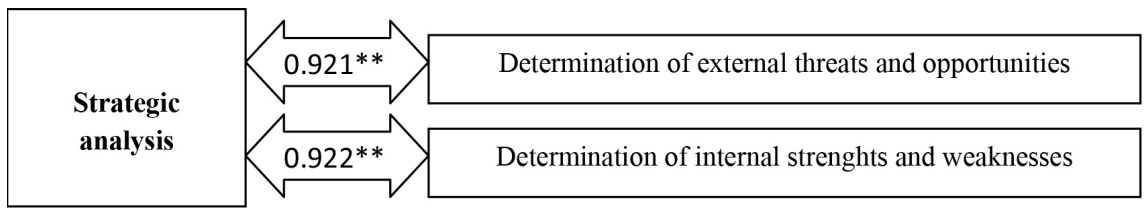

Note: * means $0.01<p<0.05 ;{ }^{* *}$ means $p<0.01$ 


\section{Fig. 6: Correlation among elements of strategic prognostication}

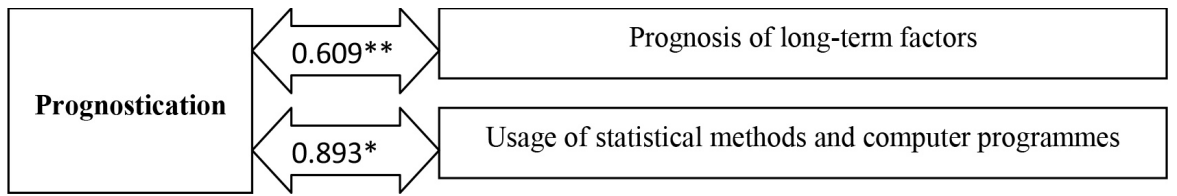

Source: own

Note: * means $0.01<p<0.05 ;{ }^{* *}$ means $p<0.01$

with the organization control activities, as well as with improvement $\left(0.841^{* *}\right.$, see Fig. 3$)$. The understanding and evaluation of prognostication are also demonstrated by the correlation of individual prognostication components with this activity (Fig. 6). Considering such research results, it could be stated that Lithuanian sport organizations are trying to prognosticate and plan their activities respectively.

Prognostication in an organization is not significantly related with the executives' active participation in this activity (see Tab. 1), but it is given sufficient attention in official documentation $\left(0.480^{*}\right.$, see Tab. 1$)$.

\section{Fig. 7: Correlation among elements of strategy's selection}

$\begin{aligned} & \text { Strategy } \\ & \text { selection }\end{aligned}$
Systems of strategy selection

Note: * means $0.01<p<0.05 ;{ }^{* *}$ means $p<0.01$

Source: own

The selection of strategy, as well as its implementation are statistically significantly correlated with each other $\left(0.845^{\star *}\right.$, see Fig. 3), with the organization results (respectively $0.673^{* *}$ and $0.715^{* *}$, see Fig. 4) and the actions of its correction and improvement (respectively $0.907^{\star *}$ and $0.862^{* *}$, see Fig. 3 ). A statistically significant and especially strong correlation was identified among the elements comprising strategy selection (see Fig. 7) and its implementation (see Fig. 8).

On the basis of the research results given in Table 1 it could be stated that strategy selection $\left(0.731^{* *}\right)$ and implementation $\left(0.800^{* *}\right)$ are connected with process of documentation.
Considering the determined correlations (Tab. 1) it could be maintained that Lithuanian sport organization give sufficient attention to selection of strategic alternatives, documentation of strategic system, budgeting and evaluation of resource availability. Still it is not quite clear how purposeful are these activities as they are insufficiently correlated with the goals set in an organization (see Fig. 3).

On the basis of the research data it could be maintained that the result created in the process of strategic planning and its implementation statistically significantly correlates with the control in an organization and the actions of correction and improvement 


\section{Fig. 8: Correlation among elements of strategy's implementation}

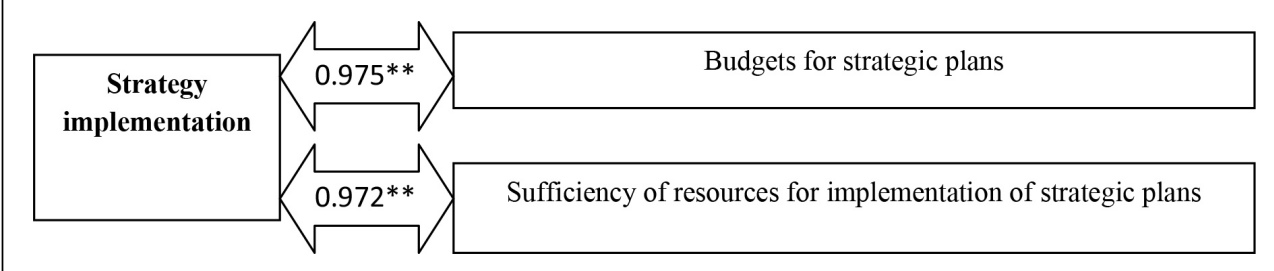

Note: * means $0.01<p<0.05 ;{ }^{* *}$ means $p<0.01$

$\left(0.814^{* *}\right.$, see Fig. 3$)$. Thus it could be stated that Lithuanian organizations are involved in strategic activities. In the opinion of Kaunas sport organizations' experts, strategic activities are performed innovatively enough. Innovativeness is understood as application of statistical programs and prognostication models in strategy creation activities.
Having looked into the result created in the analyzed organizations in more detail (see Fig. 9), it could be noted that activities comprising the result ae statistically significantly and strongly correlated with result created in an organization. The created result is documented (see Tab. 1). It could be presumed that the result created in Lithuanian sports organizations allows them to grow and improve.

\section{Fig. 9: Correlation among elements of strategy's implementation}

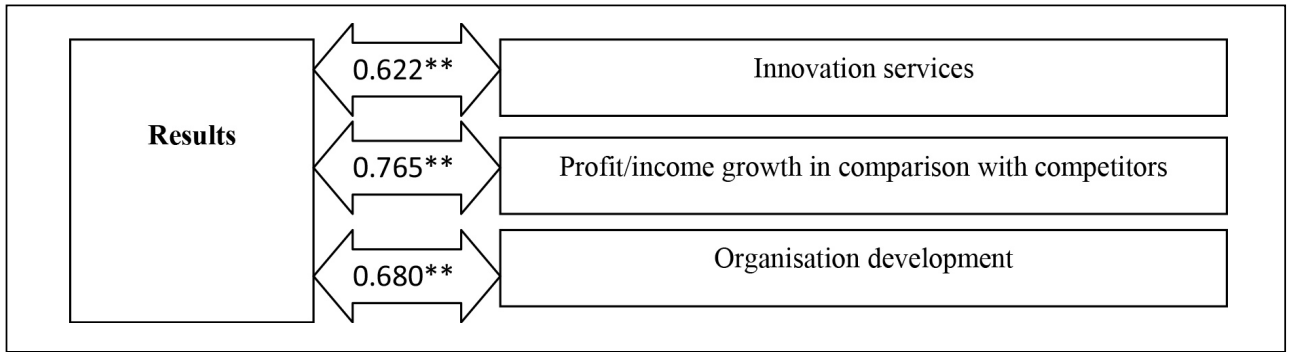

Note: * means $0.01<p<0.05 ;{ }^{* *}$ means $p<0.01$

Summarizing the research results, some important aspects of Lithuanian sport organizations' strategic planning and management could be distinguished. Firstly, the organizations under research are striving to orientate towards strategic management activities and to create results directed to the development. Secondly, organizations give sufficient attention for strategic management formalization and documentation. Thirdly, the connection between goal setting and activities of strategic planning and management is not fully perceived in the organizations. Fourthly, reasons of the latter factor may be connected with insufficient involvement of the executives in the process of strategic planning and management because a statistically significant correlation between strategic planning and management activities and active participation of the executives was not identified (see Tab. 1). 


\section{Discussion and Significance of Made Theoretical Analyzes and Research}

Strategic planning is not a new subject in a theoretical analyses and research world. Though theoretical approach made in this article is significant because of made and tested strategic planning model (see Fig. 2). In order to improve strategic management in sport organizations, in addition to the importance of executives and staff involvement in the strategic management determined in the previous research (Schaap, 2012), it is necessary to relate setting of the goals with organization results and improvement of its activities as was disclosed in the present research. Not only strategic consensus or executives' participation in the strategic management are required, but also a connection of strategic goals with activity improvement and results has to be attained. It should be noted that though executives actively participate in strategic management, not all strategic activities are given equal attention.

In spite of these drawbacks of strategic activities, sport organizations under research could be distinguished as innovative. It was not only the feedback analysis disclosed by Inamdar (2012), Wardwell (2012), Eden and Ackermann (2013) that influenced innovativeness, but also the connections between strategic activities - strategic analysis, organization results and organization improvement activities determined in the research. It is possible to achieve innovative results only by connecting strategic analysis, activities of organization improvement and documenting the results.

Theoretically created and empirically tested model of strategic planning could be used in the sport organizations with the purpose to evaluate activities of strategic planning and to reveal systemic actions needed to develop strategic management in that sport organization. This model could be applied even to other small and medium organizations developing their strategic management.

\section{Conclusions}

When analyzing strategic planning, researchers have distinguished related activities. Though the analysis showed that strategic planning activities are itemized, the process of their analysis should include distinguishing the main activities that would cover other more detailed ones. The authors suggest that the main strategic planning activities would be the following: executives' participation, setting strategic goals, documentation, analysis, prognostication, strategy selection, strategy implementation, strategy control and correction, improvement and evaluation of activities.

Strategy results reflected in service innovativeness, network, client scope, and workplace development, could be signified as an individual strategic planning element showing the significance of planning activities.

When researching the strategic planning and management aspects of sport organizations, it was discovered that the importance of strategic activities for the results of these organizations is statistically significant. Sport organizations are oriented towards all strategic management activities and are striving to create results directed to development. The following strategic activity aspects are appropriately evaluated - organizations give sufficient attention to the process of strategic management, its formalization and documentation and innovative results are achieved. The insufficient understanding of connection between goal setting and strategic planning and management activities carried out in an organization could be distinguished as a negative aspect. In order to improve strategic management in sport organizations, it is necessary to relate goal setting activity with organisation results and activity improvement.

\section{References}

Abdalkrim, G. M. (2013). The Impact of Strategic Planning Activities on Private Sector Organizations Performance in Sudan: An Empirical Research. International Journal of Business and Management, 8(10), 134-143. doi:10.5539/ijbm.v8n10p134.

Adamoniene, R., \& Andriuscenka, J. (2007). The Small and Medium-sized Enterprises: The aspects of appliance the principles of strategic management. Economic and Management, 12, 548-555.

Ahearne, M., Lam, S. K., \& Kraus, F. (2014). Performance impact of middle managers adaptive strategy implementation: The role of social capital. Strategic Management Journal, 35(1), 68-87. doi:10.1002/smj.2086.

Ancalade, P. (2009). Efficacy of corporate planning strategies on not-for-profit organizations (Doctoral dissertation). Lojola University New Orleans, New Orleans. 
Arimaviciute, M. (2004). Researches of Strategic plans creation and implementation. Public politics and administrations, 8, 29-36.

Arimaviciute, M. (2005). Strategic management of public sector institutions. Vilnius: MRU.

Beaver, G. (2000). The language of strategy. Strategic Change, 9(8), 465-468. doi:10.1002/1099-1697(200012).

Bettis, R., Gambardella, A., Helfat, C., \& Mitchell, W. (2014). Quantitative empirical analysis in strategic management. Strategic Management Journal, 35(7), 949-953. doi:10.1002/smj.2278.

Boar, B. (1995). Sun Tzu and Machiavelli on strategy. The Journal of Business Strategy, 16(1), 16-18. doi:10.1108/eb039675.

Burgelman, R. A., \& Grove, A. S. (2006). Strategic dynamics. New York: McGraw-Hill Irwin.

Damaskiene, V. (2002). Basics of management. Siauliai: Siaures Lietuva. (Original language: Damaškienè, V. (2002). Valdymo pagrindai. Šiauliai: Šiaurès Lietuva).

Demmings, B. U. L. (2008). Strategic planning in small businesses in the modeling simulation, and training industry (Doctoral dissertation). University of Phoenix, Phoenix.

Eden, C., \& Ackermann, F. (2013). Making strategy: The journey of strategic management. London: Sage.

Electronical registration system of VZ organizations. (2014, February 10). Retrieved from http://rekvizitai.vz.lt/.

Espinosa, W. R. (2009). Collaborative Strategic Planning: A Mixed Methods Study of Models and Superintendents' Perspectives (Doctoral dissertation). Loyola Marymount University, Loyola Marymount.

Fitzenz, J. (2000). The ROI of human capital. New York: Amacom.

Forouzandel, L. (2005). Strategic Management. Tehran: Payam university press.

Gudonavicius, L., Bartoseviciene, V., \& Saparnis, G. (2009). Imperatives for enterprise Strategists. Inzinerine EkonomikaEngineering Economics, 61(1), 75-82.

Hambrick, D. C., \& Frederickso, J. W. (2005). Are you sure you have a strategy? Academy of Management Executive, 19(4), 5162. doi:10.5465/AME.2001.5897655.

Hutzschenreuter, T., \& Kleindienst, I. (2006). Strategy-process research: What have we learned and what is still to be explored.
Journal of Management, 32(5), 673-719. doi:10.1177/0149206306291485.

Ibrahim, N., Angelidis, J. P., \& Parsa, F. (2004). The Status of Planning in Small Businesses. American Business Review, 22(2), 52-60.

Inamdar, S. N. (2012). Alignment of Strategy with Structure Using Management Control Systems. Strategic Management Review, 6(1), 1-26.

Yusuf, A., \& Saffu, K. (2005). Planning and performance of small and medium enterprise operators in a country in transition. Journal of Small Business Management, 43(4), 480-497. doi:10.1111/j.1540-627X.2005.00148.x.

Jasinskas, E., Reklaitiene, D., \& Svagzdiene, B. (2013). Evaluation of service quality in fitness centres. Transformations in Business \& Economics, 12(1), 108-124.

Jeffrey, W. A. (2013). The Dynamics of Strategy: Mastering Strategic Landscapes of the Firm. Strategic Management Review, 7(1), 110-111.

Jeseviciute-Ufartiene, L. (2010). Organization self-development based on mind activity expansion in management. Management theory and studies for rural business and infrastructure development, 5(24), 55-62.

Jeseviciute-Ufartiene, Importance of planning in management developing organization. Journal of Advanced Management Science, 23, 176-180. doi:10.12720/joams.2.3.176-180.

Jeseviciute-Ufartiene, L., MejeryteNarkeviciene, K., \& Widelska, U. (2014). Organizational development based on leader's self-development theory and practice. Transformations in Business \& Economics, 13(2A), 506-524.

Jucevicius, R. (1998). Strategic development of organization. Kaunas: World Lithuanian centre of culture, science and education.

Khoong, C. M. (1996). An integrated system framework and analysis methodology for manpower planning. International Journal of Manpower, 7(1), 26-46. doi:10.1108/01437729610110602.

Kvedarvicius, J. (2006). Organizational Development Management. Kaunas: VDU.

Lithuanian sport statistics document. (2013). Department of Physical education and sports under the government of the Republic of Lithuania. Information centre of Lithuania sports. Retrieved from http://www.sportinfo.It/dokumentai/leidiniai/sp_ 
statistikos_metrastis/2013_Lietuvos_sporto_ statistikos_metrastis.pdf.

Melnikas, B., \& Smaliukiene, R. (2007). Strategic management. Teaching book. Vilnius: General Jonas Zemaitis Lietuvian War Academy.

Matthews, J. R. (2005). Strategic planning and management for library managers. CA: Libraries Unlimited.

Mintzberg, H., Ahlstrand, B., \& Lampel, J. (2005). Strategy Safari: A Guided Tour through the Wilds of Strategic Management. US: Simon and Schuster.

Miles, R. E., \& Snow, C. C. (1978). Organizational strategy, structure, and process. New York: McGraw - Hill.

Moulds, P. (2012). Exploration of the balanced scorecard as a tool for performance measurement and strategic planning in higher education development (Doctoral dissertation). University of Mississippi, Mississippi.

Natzel, R. J. (2010). The development of a business plan for an e-commerce website operating in the health, fitness and sport industry (Doctoral dissertation). California State University, California.

Parnell, J. A. (2003). Five critical challenges of strategy making. SAM Advanced Management Journal, 68(2), 15.

Porter, M. E. (1996). What is strategy? Harvard Business Review, 74, 61-78.

Pugh, J., \& Bourgeois, III L. J. (2011). 'Doing' strategy. Journal of Strategy and Management, 4(2), 172-179. doi:10.1108/17554251111128637.

Registration system of Organizations. (2014, February 10). Retrieved from http://www.sportoklubai.It/.

Rieker, M. (2004). How cities may grow non - U.S. profit to 50\%. American Banker, 169(147), 1-3.

Rudzikiene, V. (2003). Statistic technologies in law and management: practical works. Vilnius: Press of Lithuana Law University.

Schaap, J. I. (2012). Strategy Implementations - Can Organizations Attain Outstanding Performance? Strategic Management Review, 6, 98-121.

Schriefer, A. E. (2005). Workplace strategy: What it is and why you should care. Journal of Corporate Real Estate, 7(3), 222-243. doi:10.1108/14630010510631081.

Scott, R. (2003). Organizations rational, natural, and open systems. Upper Saddle River, NJ: Prentice - Hall.
Searcey, C. J., Snodgrass, J. T., \& Copple, W. B. (2010). Good to Great: Do award winning schools meet successful school criteria? (Doctoral dissertation). Saint Louis University, Saint Louis.

Seeman, M. (1972). On the Meaning of Alienatio. In P. Lazarsfeld, A. Pasanella, \& M. Rosenberg (Eds.), Continuities in the Language of Social Research. New York: Free Press.

Stewart, K. S. (2002). Formal business planning and small business success: A survey of small business with an international focus. Journal of American Academy of Business, 2(1), 42-46.

Streimikiene, D., \& Kiausiene, I. (2012). Gender equality measurements in Lithuania. Transformations in Business \& Economics, 11(1). 167-183.

Svagzdiene, B., Krikstaponyte, I., Simanavicius, A., \& Istomina, N. (2015). The assessment of recreational services, promoting healthy lifestyle, at water bodies: case of Lithuania. Transformations in Business \& Economics, 14(2B). 414-429.

Tamasevicius, V. (1996). Integrative view on the concept of business strategy. Ekonomika, 40, 123-147.

Thompson, A. A., Strickland, A. J., \& Gamble, J. E. (2007). Crafting \& executing strategy (15th ed.). Boston: McGraw-Hill Irwin.

Vargo, J., \& Seville, E. (2011). Crisis strategic planning for SMEs: finding the silver lining. International Journal of Production Research, 49(18), 5619-5635. doi:10.1080/00207543.2011.563902.

Vasiliauskas, A. (2004). Strategic management of national economic expansion. Money studies, 3, 5-18.

Wardwell, S. E. (2012). A Strategic Model for INGO Accountability Systems (Doctoral dissertation). Portland State University, Portland.

Wang, C., Walker, E. A., \& Redmond, J. L. (2007). Explaining the lack of strategic planning in SMEs: The importance of owner motivation. International Journal of Organisational Behaviour, 12(1), 1-16.

Williams, A. P. (2012). Assessment and strategic planning to determine the growth feasibility of a distance based rural baccalaureate nursing program (Doctoral dissertation). University of South Karolina, South Karolina.

Wittmann, R., \& Reuter, M. (2013). Strategic planning: How to deliver maximum value 
through effective business strategy. UK: Kogan Page Publishers.

Volovikov, B. (2011), Improvement of Methods of Strategic Planning at the Example of Industrial Enterprises. Montenegrin Journal of Economics, 7(1), 79-89.

Vveinhardt, J., Gulbovaitè, E., \& Streimikiene, D. (2016). Different Values Forms in Organization: is the Congruence Possible? Montenegrin Journal of Economics, 12(2), 117-129. doi:10.14254/1800-5845.2016/12-1/8.

Vveinhardt, J., Andriukaitiene, R., \& Grancay, M. (2015). The preparation of companies in developing regions to become socially responsible: management culture assessment by employees. Transformations in Business \& Economics, 14(2B). 494-514.

Zafar, F., Butt, A., \& Afzal, B. (2014). Strategic Management: Managing Change by Employee Involvement. International Journal of Sciences: Basic and Applied Research, 13(1), 205-217. doi:10.5539/ijbm.v8n10p134.
Assist. Prof. Jovica Petkovic, Ph.D. University of Montenegro

Faculty for Sport and Physical Education

Niksic Montenegro Jovica.petkovic@gmail.com

prof. Edmundas Jasinskas, Ph.D. Lithuanian Sports University Faculty of Sport Education Department of Sport Management Economics and Sociology edmundas.jasinskas@Isu.It

Laima Jesevičiūtè-Ufartienè, Ph.D. Lithuanian Sports University Faculty of Sport Education Department of Sport Management Economics and Sociology laima1981@yahoo.com 


\title{
Abstract
}

\section{SIGNIFICANCE OF STRATEGIC PLANNING FOR RESULTS OF SPORT ORGANISATION}

\author{
Jovica Petkovic, Edmundas Jasinskas, Laima Jesevičiūtè-Ufartienè
}

The article focuses on the application of strategic planning activities in a sport organization. Firstly, strategic planning activities are distinguished and their significance for organizations analyzed. The following activities are emphasized - setting of strategic goals, analysis, and prognostication, the choice of strategy and its implementation, as well as the feedback. The research deals individually with the issue of management participation in the strategic planning activities and raises the question of their documentation. The significance of strategic planning activities can be identified through the achieved strategic results, i.e. innovativeness and development. The article presents an empiric research with Kaunas city sport clubs as its participants.

Though the analysis showed that strategic planning activities are itemized, the process of their analysis should include distinguishing the main activities that would cover other more detailed ones. Strategy results reflected in service innovativeness, network, client scope, and workplace development, could be signified as an individual strategic planning element showing the significance of planning activities.

When researching the strategic planning and management aspects of sport organizations, it was discovered that the importance of strategic activities for the results of these organizations is statistically significant. Sport organizations are oriented towards all strategic management activities and are striving to create results directed to development. The following strategic activity aspects are appropriately evaluated - organizations give sufficient attention to the process of strategic management, its formalization and documentation and innovative results are achieved. The insufficient understanding of connection between goal setting and strategic planning and management activities carried out in an organization could be distinguished as a negative aspect.

Key Words: Strategic planning, strategic results, sport organization, innovation, organizational development.

JEL Classification: M10, M12, M21.

DOI: 10.15240/tul/001/2016-4-005 